\title{
Bringing the Models Together: An Empirical Approach to Combining Variables Used to Explain Health Actions
}

\author{
K. Michael Cummings, ${ }^{1}$ Marshall H. Becker, ${ }^{1}$ and \\ Marla C. Maile ${ }^{1}$
}

Accepted for publication: January 11,1980

Considerable confusion has existed among researchers with regard to the selec-
tion of a particular model of health behavior for study, and many investigators
have long felt that the actual number of truly distinct concepts relevant to ex-
plaining health-related actions is considerably lower than the large number of
variables currently employed. This paper explores selected approaches and
models which have been advanced to explain health actions, in terms of struc-
tural similarities and differences identified by a panel of judges who are the re-
levant experts in this field. Judges were asked to partition a set of 109 variables,
representing 14 different models, into $12-14$ groups on the basis of similarity.
The structural similarities among the variable groups were evaluated using
Smallest Space Analysis. Six interpretable factors emerged from the analyses:
(1) accessibility to health care, (2) evaluation of health care, (3) perception of
symptoms and threat of disease, (4) social network characteristics, (5) knowledge
about disease, and (6) demographic characteristics. The results of the study
provide a first step in developing a unified framework for explaining health
actions.

KEY WORDS: health-behavior predictor models; access, psychosocial, and network varjables; Smallest Space Analy sis.

This research was supported in part by Grant No. HD 00237 from the National Institute of Child Health and Human Development.

${ }^{1}$ Department of Health Behavior and Health Education, School of Public Health, The University of Michigan, Ann Arbor, Michigan 48109. 


\section{INTRODUCTION}

With the shifting emphasis in health care toward a focus on prevention and early detection of disease, the effectiveness of many health programs is becoming increasingly dependent upon the willingness of individuals to accept a more active role in caring for their health. Despite the fact that the individual stands to benefit the most from the success of health programs, participation in screening, immunization, and other preventive health efforts, as well as rates of individual compliance to prescribed medical therapies, has been relatively low (Barofsky, 1977; Sackett and Snow, 1979).

There is no single or simple answer to the question of why some people choose to take an active role in caring for their health, while others do not. The many different efforts of behavioral scientists to both identify and explain the determinants of voluntary health-related behaviors attest to the fact that the underlying problem is multifaceted and complex. McKinlay's (1972) review of the literature on the use of health services, for example, identified six approaches for explaining utilization behavior: economic, sociodemographic, geographic, sociopsychological, sociocultural, and organizational.

Over the past two decades, a number of theoretical frameworks have appeared which attempt to account for health actions. Most notable, in terms of predictive ability and frequency of citation, have been the models proposed by Andersen (1968), Anderson and Bartkus (1973), Antonovsky and Kats (1970), Fabrega (1973, 1974), Green (1975), Hochbaum (1958), Kar (1977, 1978), Kasl and Cobb (1966a,b) (actually two models, one for "health" and one for "illness" behaviors), Kosa and Robertson (1975), Langlie (1977), Mechanic (1968), Rosenstock (1966) [while the Rosenstock and Hochbaum models were derived from the same body of theory, each, as published, contains variables not found in the other - cf. Kirscht et al. (1978)], and Suchman (1966).

Although these 14 models differ considerably in the theoretical perspectives used to explain behavior, in the types of behaviors to be explained, and in the terms employed to label the different dimensions and variables, the general classes of factors included in each of the models appear, at least superficially, to be quite similar. For example, all of these formulations possess one or more variables which represent the individual's evaluation of various health actions (e.g., "treatment benefits," "value of health services," and "advantages of action"). The models advanced by Mechanic, Rosenstock, Langlie, Kasl and Cobb, Fabrega, Hochbaum, Andersen, Anderson and Bartkus, Antonovsky and Kats, and Kosa and Robertson include variables which assess the individual's perception of symptoms in relation to disease threat (e.g., "perceptual salience of symptoms," "assessment of symptoms," "symptom sensitivity," and "perceived susceptibility to illness conditions"). Finally, 10 of the 14 models contain variables which reflect factors that facilitate or inhibit access to health care (e.g., "availability of treatment resources," "monetary costs," "awareness of health 
facilities," and "distance to health facilities"). The student of the health-behavior literature might therefore reasonably suspect, upon examination of extant models, that the actual number of truly distinct concepts believed to be important in understanding and predicting health-related behaviors is far lower than the more than 100 variables these models have generated. A listing of the variables and a brief summary of each model are presented in Table I.

But, while the variables can be combined into a limited number of groupings on a face-validity basis, it might be argued that the creators of the models are aware of more subtle aspects and distinctions which, if made explicit, would require that these like-appearing variables not be viewed as highly comparable. (Such an approach also provides a conservative test of intermodel comparability, since one might expect each model builder to wish to preserve what are felt to represent the unique characteristics and contributions of his/her model to the field.) Thus, any attempt to reduce the great multiplicity of concepts and variables (in order to move toward a more simple, unified set of compatible concepts to explain health-related behaviors) must be based upon data obtained from the various model builders themselves.

The purposes of this paper are to explore the selected approaches and models which have been advanced to explain health actions in terms of structural similarities and differences identified by a panel of judges who are relevant experts in this field and to use these expert evaluations to construct a general taxonomy of factors affecting health-related behaviors. The latter objective should be useful for at least two reasons. First, these broader dimensions can provide a more complete framework for making decisions about the types of variables which ought to be included in future research on health behavior. Second, a greater understanding of the structure of a particular class of variables should aid in the development of more reliable and precise measures of the concept they are supposed to represent.

\section{METHOD}

The data analyzed here are derived from judges' assessments of a complete listing of the variables included in each of the 14 models presented in Table I. Eighteen variables found to have been labeled and defined in exactly the same way in two or more models were dropped from the listing. A total of 109 different variables was retained for use in the study. ${ }^{2}$ A description of each of the variables is presented in the Appendix.

\footnotetext{
${ }^{2}$ Ultimately, 10 of the rated variables were excluded from the analyses because they were classified as "miscellaneous" by five of eight judges; these variables were "competing possible interpretation of symptoms," "residential mobility," "illness recognition and labeling," "selection of treatment plans," "treatment plans," "response to illness," "classification of manipulative actions," "complexity of behavior," "trialability," and "observability."
} 


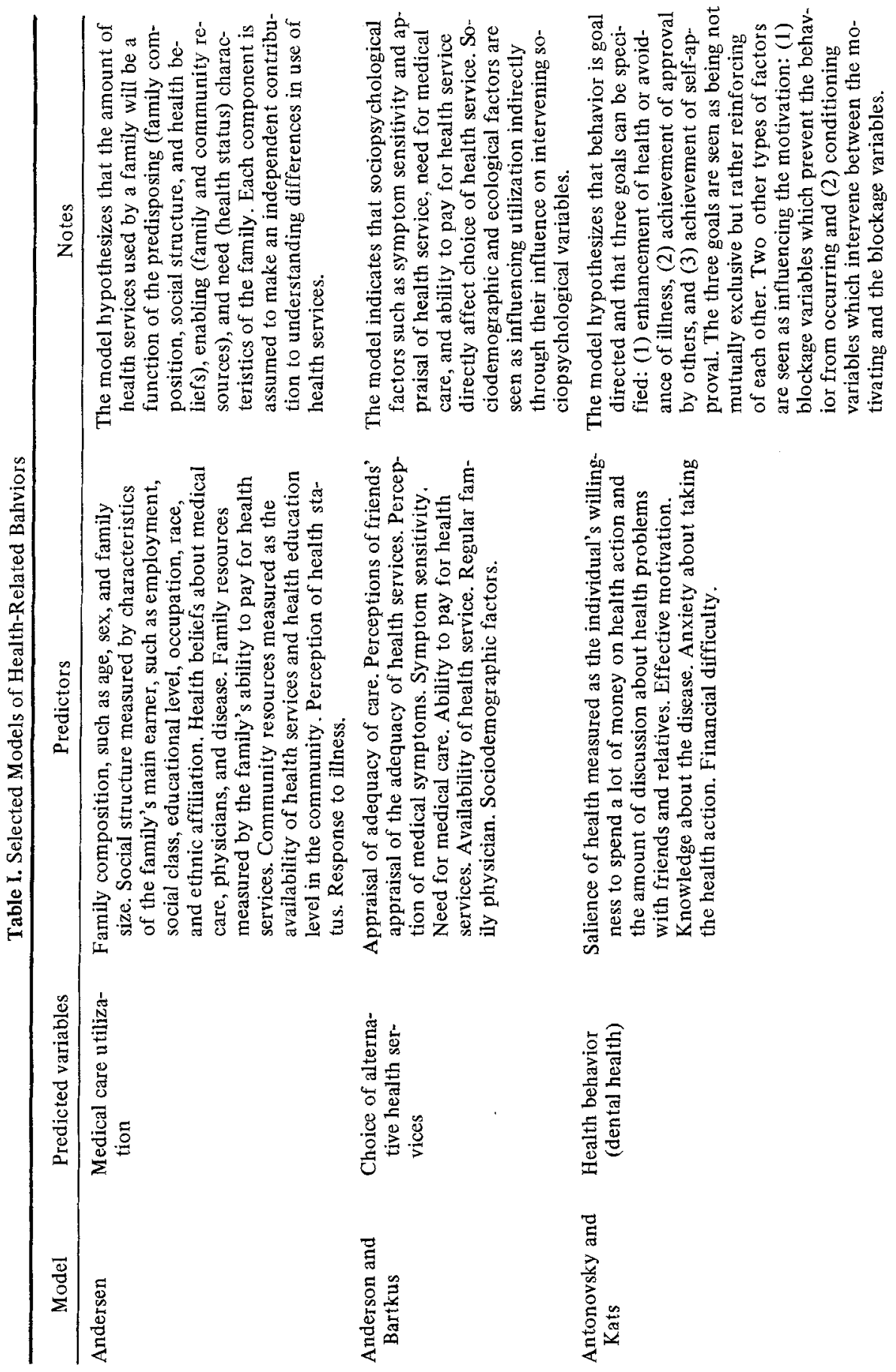




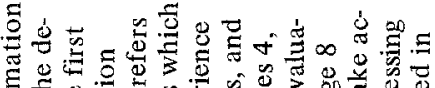

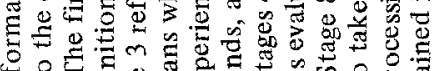

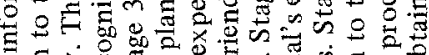

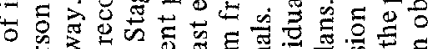

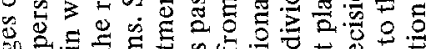

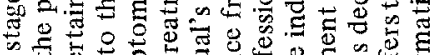

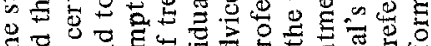

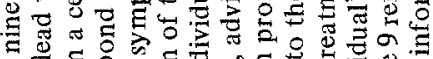

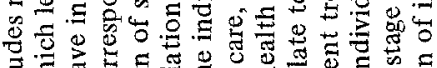

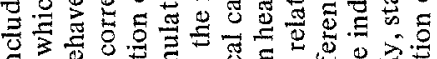

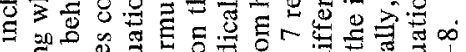

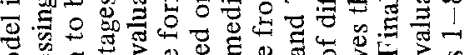

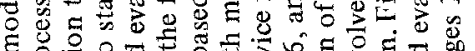

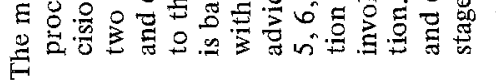

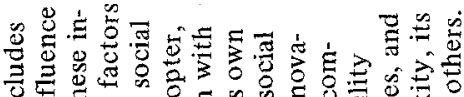

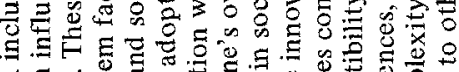

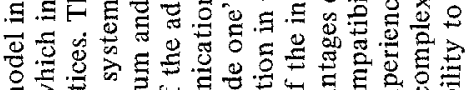

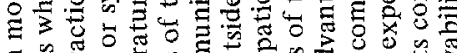

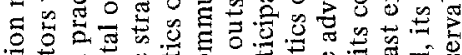

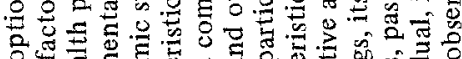

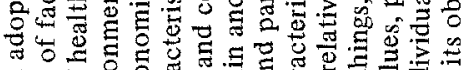

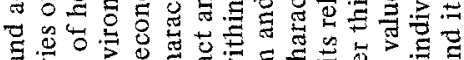

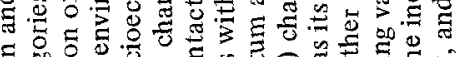
5

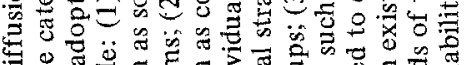
要 \&

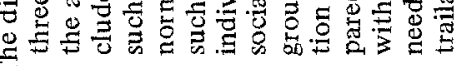
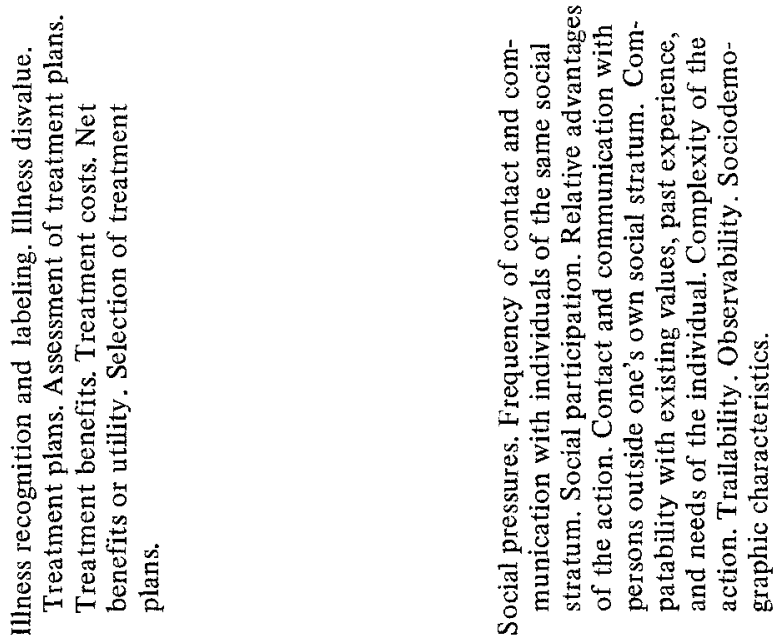

总

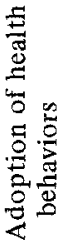

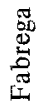




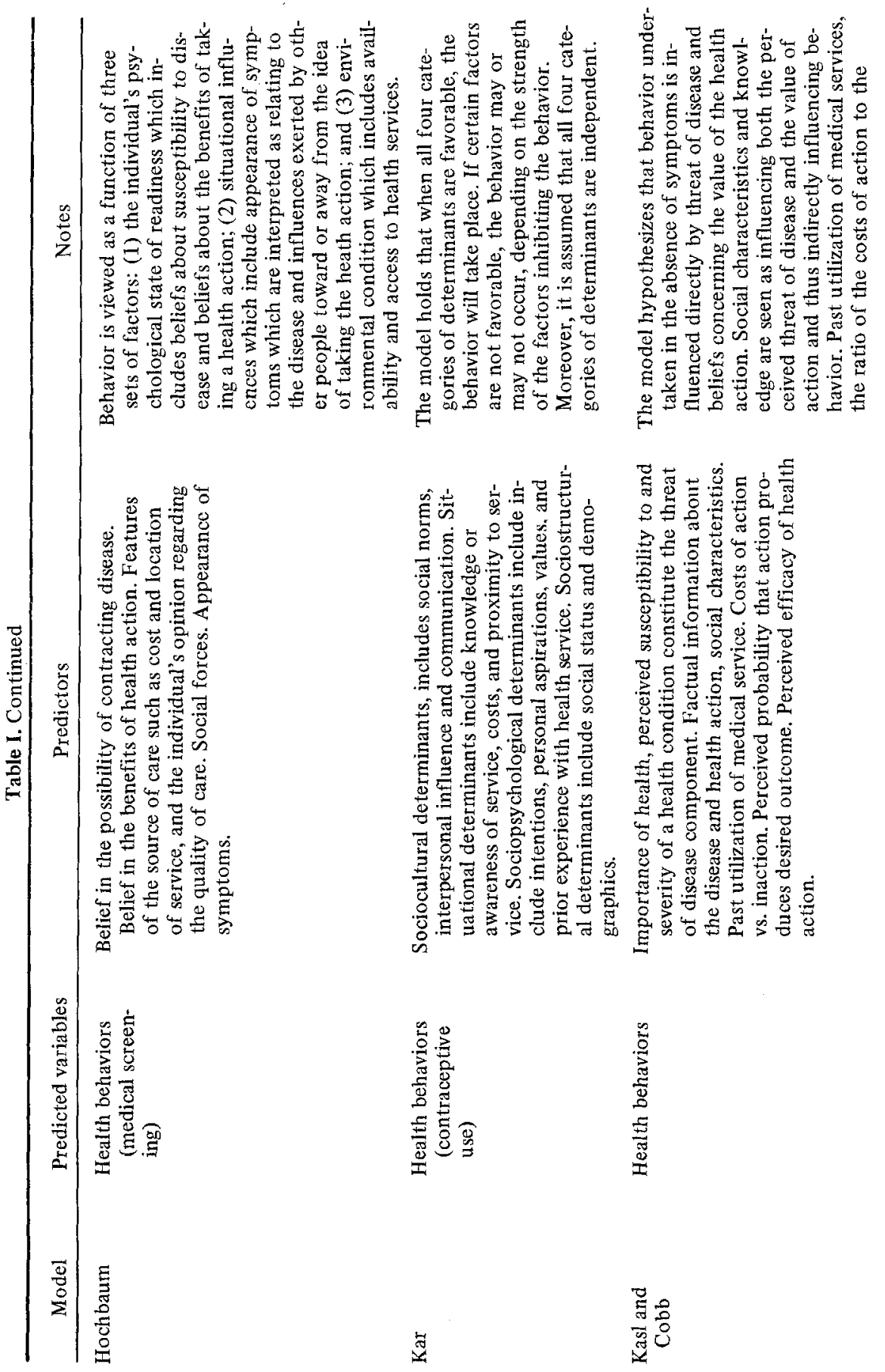




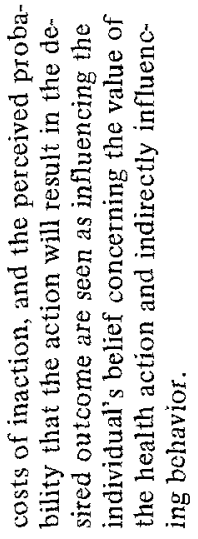

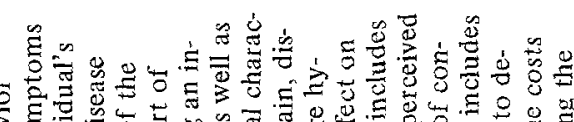

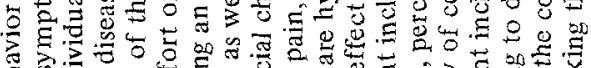

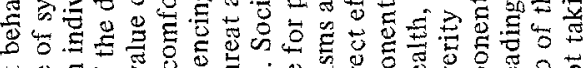

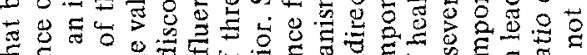

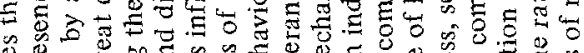

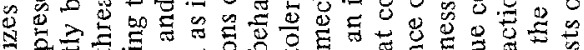
क人

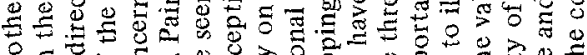

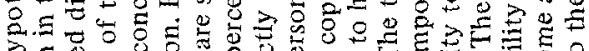

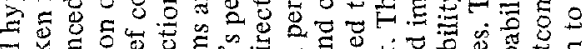

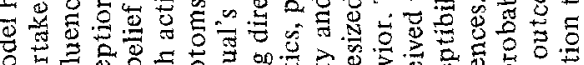

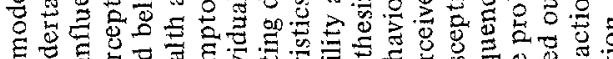

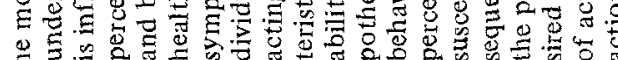
E

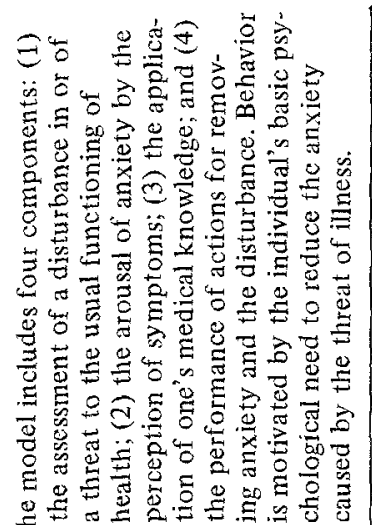

Z

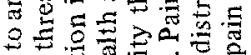

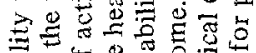

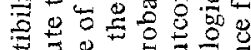

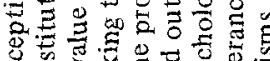

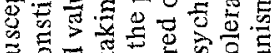

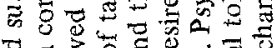

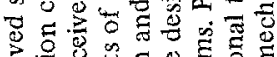

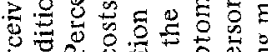

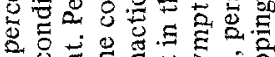
ง

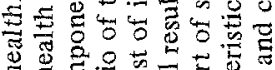

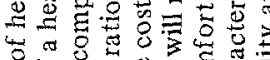

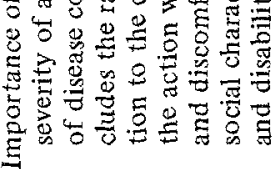

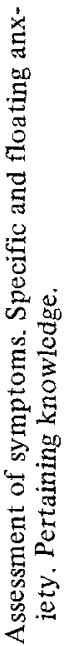

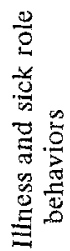

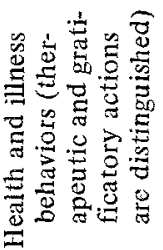

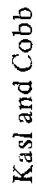

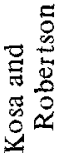




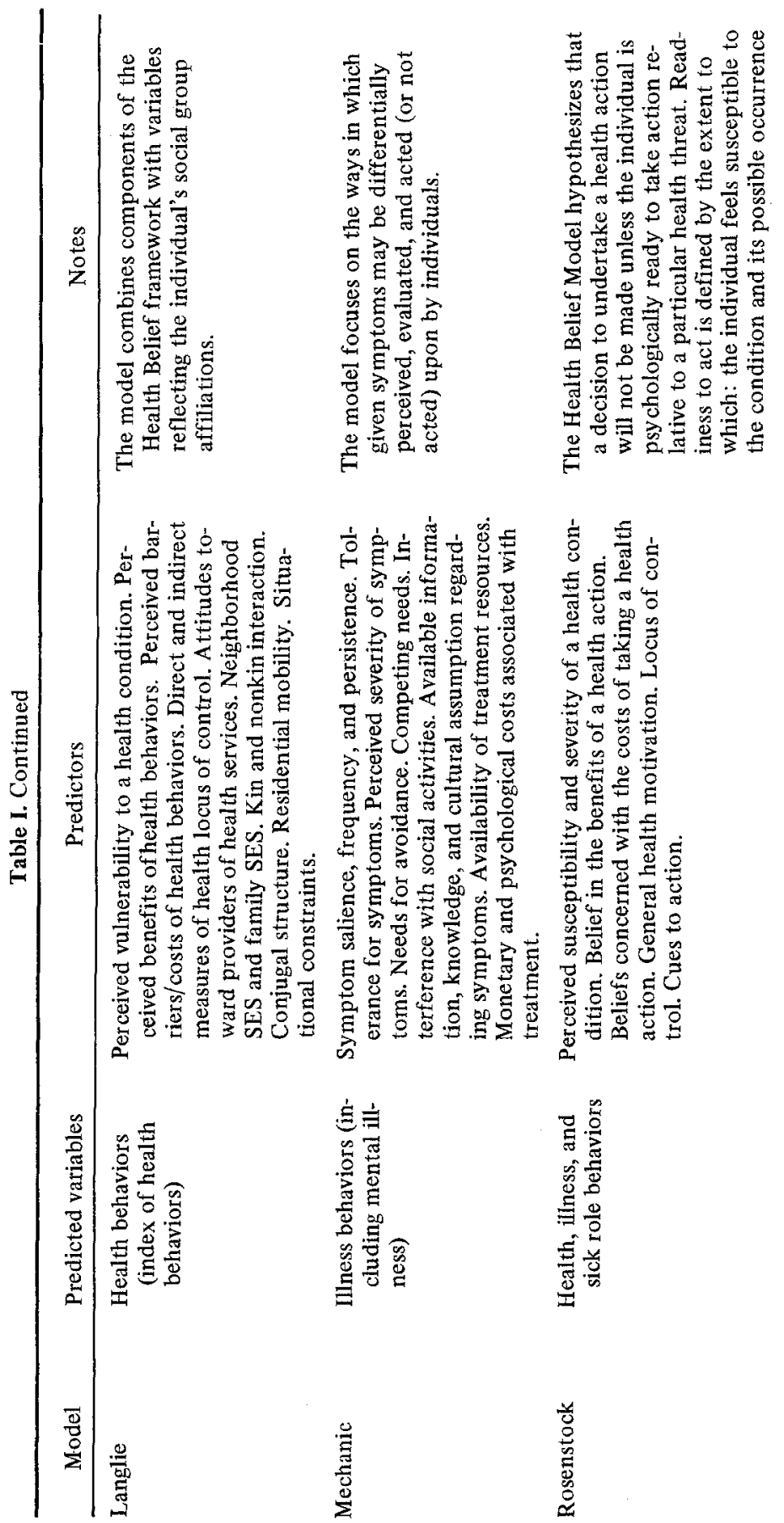




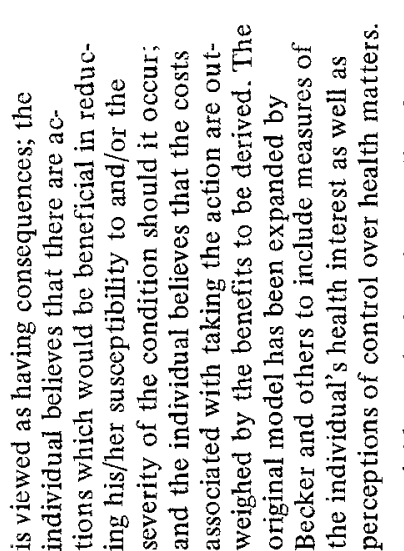

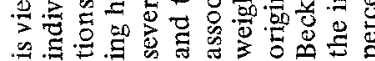
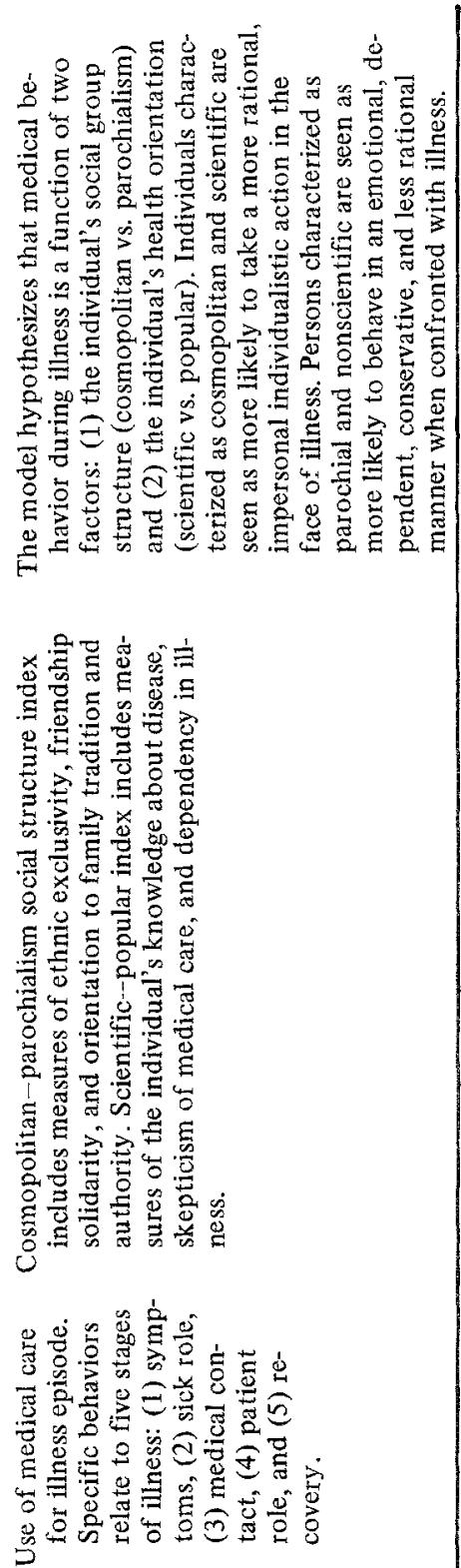
The investigators attempted to recruit, as judges, the 11 living (in the United States) authors of the different models compared in this study; 8 of these 11 model builders agreed to participate in the project. A complete set of study materials was sent to each judge, to be acted upon and returned by a specified date.

The task involved having each judge compare the set of 109 variables and place them into categories on the basis of their similarity. The name and definition (as they appeared in publications) of each variable were presented on a $3 \times 5$-in. index card. (The model from which any particular variable was obtained was not identified to the judges.) Judges were provided with an instruction sheet explaining the procedure as follows:

\begin{abstract}
You have received a set of 109 index cards. On each card is the name (in capital letters) and definition of a variable which has been employed in research on individuals' health-related behaviors. We would like to know how you would group these variables on the basis of their apparent similarity. Look at each of the variable cards. Then sort the cards into distinct groups on the basis of what you judge to be their degree of similarity. You may consider any aspect of the variables in deciding whether they are similar or not. You may create as many groups as you wish, although 12 to 14 would be a preferable maximum. If you have any variables left over which you feel cannot be assigned to any of the existing groups, you can create a miscellaneous group.
\end{abstract}

Our interests required the performance of two distinct analytic tasks: (1) identification of the structural similarities among variables included in the 14 models developed to explain health-related behaviors, and (2) determination of the amount of agreement in the judges' partitioning of the variables.

Structure was identified using Smallest Space Analysis (SSA), one of several methods for nonmetric multidimensional scaling (Guttman, 1968; Lingoes, 1977). The input datum for the SSA was a measure of relatedness between pairs of variables. This measure involved aggregation, across judges, of the number of times a pair of variables was grouped together. (Since there were eight judges, the number of times any two variables could be grouped together ranged from a minimum of 0 to a maximum of 8.) With this input, SSA proceeds to approach iteratively that configuration of points in multidimensional space which best represents, simultaneously, all pairwise relations among variables. Thus, variables which were grouped together frequently (suggesting that they tap the same concept or highly related ones) are placed close to one another and variables that are independent are placed far apart.

The usefulness of the multidimensional scaling model is that it gives a compact multidimensional representation of the information in the association matrix in a format which has intuitive meaning because of its strong analogy to our understanding of spatial distances between physical objects (Napier, 1972). However, the more compact the representation of points (i.e., the fewer the number of dimensions), the greater the chance of distorting the data, because it may become more difficult to distinguish among groups of variables that are only weakly interrelated. Of course, given a large number of variables, it is not 
necessary to achieve a perfect match between the distances of points in a smalldimensioned space and the rank order of the original pairwise associations between variables; rather, the principle of parsimony argues for attaining a compact solution while retaining a satisfactory level of consistency. The Shepard-Kruskal stress coefficient provides a measure of the consistency between the interpoint distances in the multidimensional space and the relationship among variables (Shepard et al., 1972). Low values of stress imply a high similarity; a 1.0 stress coefficient indicates a zero relationship between the plotted points in multidimensional space and the association among variables, while a stress coefficient of 0.0 implies a perfect match.

Two criteria were used to decide on the optimum number of dimensions: (1) the minimum number of dimensions with a satisfactory level of fit (i.e., a stress coefficient less than 0.10 ), and (2) the interpretability of the different solutions. After several trials, it was determined that a three-dimensional space permitted an adequate portrayal of the structure (this three-dimensional solution yielded a stress coefficient $=0.06$ ).

The second part of the analysis task was to determine the amount of agreement between judges, thus providing a measure of the reliability of the multidimensional scaling solution. Cohen's $\kappa$ statistic was employed to measure interjudge agreement. The $\kappa$ statistic defines reliability as the ratio of the difference between the proportion of observed agreement $\left(P_{\mathrm{O}}\right)$ and the proportion of agreement expected by chance alone $\left(P_{\mathrm{c}}\right)$ to the total proportion of agreement possible minus chance (Fleiss, 1973):

$$
\kappa=\left(p_{\mathrm{O}}-p_{\mathrm{c}}\right) /\left(1-p_{\mathrm{c}}\right) .
$$

The $k$ statistic can range from -1 to +1 . High positive coefficients indicate substantial agreement, coefficients around zero imply little agreement, and high negative coefficients indicate substantial disagreement between judges.

The extent of agreement was determined by summing the number of times that any two judges were in agreement about whether or not any two variables went together. For example, for any pair of variables:

Judge 1

\begin{tabular}{|c|c|c|c|}
\hline & The variables: & Go together & $\begin{array}{l}\text { Do not go } \\
\text { together }\end{array}$ \\
\hline & Go together & & \\
\hline & $\begin{array}{l}\text { Do not go } \\
\text { together }\end{array}$ & & \\
\hline
\end{tabular}


For each pair of judges, all possible combinations of the study variables (taken two at a time) were evaluated for agreement. Using 99 variables, this created 9801 pairs $(99 \times 99)$. However, since it would be redundant to pair a variable with itself, this figure is reduced by 99 , so that the total number of variable pairings upon which agreement was evaluated between any two judges (i.e., by the $\kappa$ statistic) was 9702 .

\section{FINDINGS}

We will begin the presentation of findings with the configuration for the 99 variables used as input to SSA, noting how the different models are, in fact, viewed as similar. Following this, we shall examine the stability of the multidimensional scaling solution by comparing each judge's partitioning of the variables.

\section{Overall Structure for the Model Variables}

Figure 1 displays the three-dimensional structure for the 99 variables which was yielded by the SSA. Several salient findings may be noted.

First, the variables seem to be arrayed in six distinct categories (these same clusters also appeared, although somewhat less distinctly, in the two-dimensional solution). We have assigned a label to each category in an attempt to represent the variables which they contain. These categories include the following clusters of variables: "perception of illness" and "threat of disease" variables located in the upper left portion of the figure, "knowledge of disease" variables located in the center, "social network" variables located in the upper right portion, "demographic" variables located to the right of center, "access to health care" variables located in the lower right portion, and "attitude toward health care" variables located in the lower left portion of the figure. Moreover, within several of these larger groupings there exist subclusters of items which help to define further the meanings of the underlying categories. For example, the cluster of "accessibility" variables can be subdivided into two distinct groups: (1) items on the financial costs of health care (v65, v81, v89) and (2) items on the availability of health services (v9, v26, v82). Similarly, the variables comprising the social network cluster can be further subdivided into three meaningful groups: (1) items dealing with social interaction patterns (v37, v95, v96, v98), (2) items on social structural characteristics (v16, v17, v18, v25, v38, v70, v72, v73), and (3) items pertaining to social norms (v57, v94). Finally, the variables included in the "health threat" cluster can be subdivided into two groups: (1) items on perception and evaluation of symptoms (v1, v2, v30, v31, v50, v55, v80, v90, v91) and (2) items on response to illness (v5, v7, v47, v48, v49). 


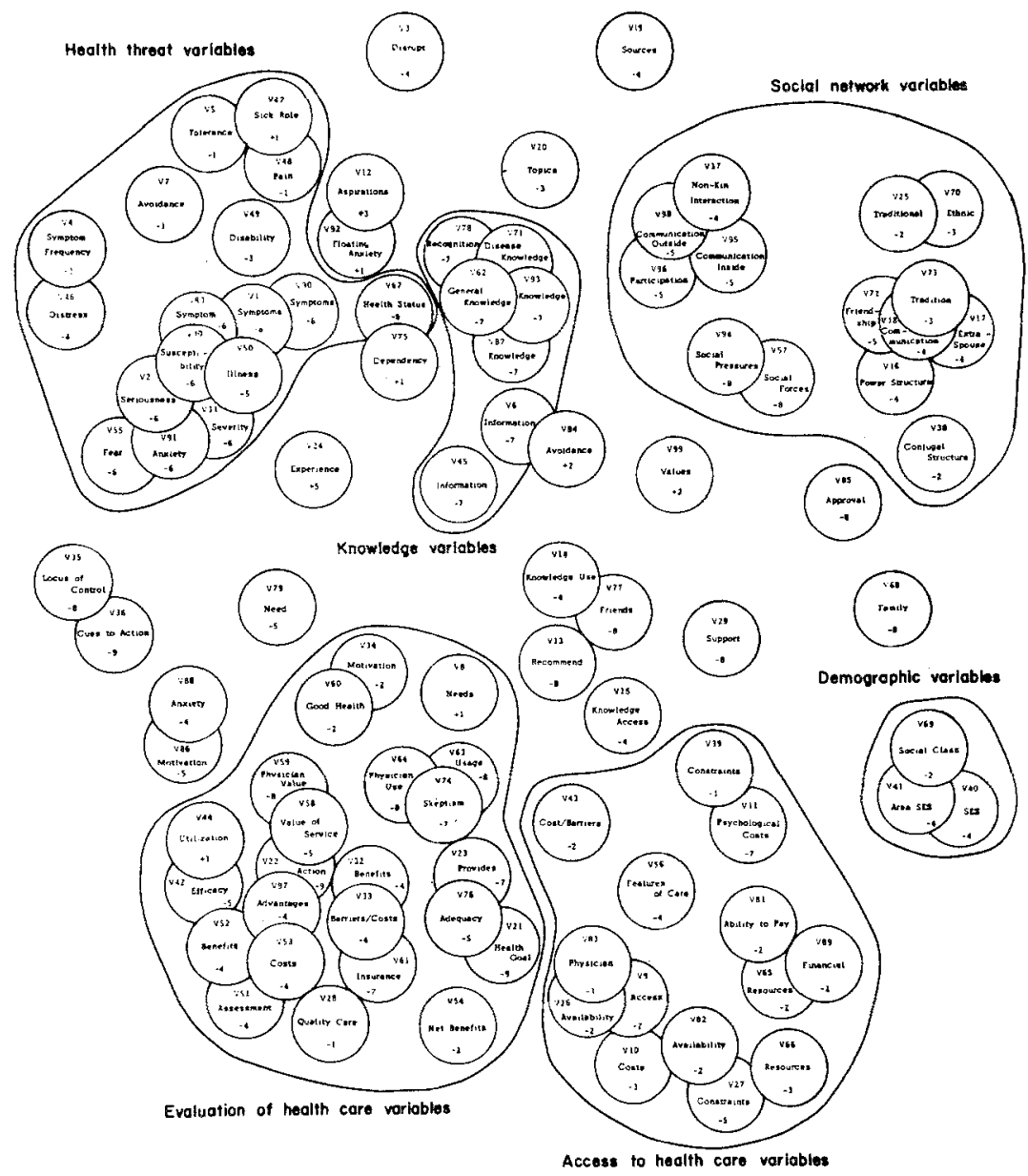

Fig. 1. Three-dimensional structure of 99 correlates of individual health-related behaviors. Note: Signed numbers indicate the position of the variable on the third dimension.

Second, the analyses revealed several items which did not fall within the six categories of variables just identified. With respect to the first two axes of the figure (i.e., the vertical and horizontal dimensions), it is apparent that the items dealing with support from friends and family (v13, v29, v68, v77, v85) are scattered about the right-center portion of the structure; however, they are highly related in the third dimension. Items pertaining to knowledge about health services $(\mathrm{v} 14, \mathrm{v} 15)$ are located midway between the cluster of knowledge of disease variables and the cluster of access to health service variables in both the second and the third dimensions. On the third dimension (which runs "in 
front of" to "in back of" the plane of the figure), the locus of control (v35), cues to action (v36), need for medical care (v79), effective motivation (v86), and anxiety (v88) items are located outside and well back from the "evaluation" category, the general motivation (v34) and belief in value of good health (v60) items are located within the category but modestly back, while the competing needs item (v8) is located slightly in front of the other evaluation of health care variables. Items which remain substantially independent of other items in the figure include disruption of social activities (v3), sources of information (v19), topics on which information is sought (v20), past experience with illness and/or health action (v24), avoidance of ill health (v84), and compatability of an action with existing values (v99). Failure of these items to cluster with other items in the figure reflects disagreement among judges on where to categorize these variables.

Third, the distance between clusters provides an indication of the degree of association obtained between categories of variables. For example, the knowledge of disease items are located more closely to items pertaining to perception and evaluation of symptoms than to items on access to health care. Items on evaluation of health care are located more closely to items on access to health care than to items dealing with social interactions, social structure, or social norms. Demographic variables are associated most closely with the accessibility items and are quite distinct from the cluster of variables dealing with perception of illness.

\section{Interjudge Agreement}

Having examined the structural similarities of the variables contained in the different models, we can now turn to the question of the reliability of the multidimensional scaling solution. The agreement coefficients on judges' partitioning of the set of 99 variables are presented in Table II. The coefficients are all positive (average $k=0.35$ ) and significantly different from chance agreement.

Table II. Interjudge Agreement $\kappa$ on the Partitioning of 99 Items $^{a}$

\begin{tabular}{lccccccc}
\hline & Judge 1 & Judge 2 & Judge 3 & Judge 4 & Judge 5 & Judge 6 & Judge 7 \\
\hline Judge 2 & 0.45 & & & & & & \\
Judge 3 & 0.29 & 0.45 & & & & & \\
Judge 4 & 0.38 & 0.50 & 0.48 & & & & \\
Judge 5 & 0.35 & 0.52 & 0.63 & 0.59 & & & \\
Judge 6 & 0.17 & 0.30 & 0.29 & 0.37 & 0.35 & & \\
Judge 7 & 0.27 & 0.38 & 0.36 & 0.34 & 0.38 & 0.48 & \\
Judge 8 & 0.12 & 0.31 & 0.23 & 0.19 & 0.32 & 0.24 & 0.19 \\
\hline
\end{tabular}

$a_{\text {All coefficients are significant }(p<0.01)}$ beyond chance level agreement. 
That is, the observed coefficient reflects a moderate amount of nonchance agreement among the eight judges, providing evidence for the stability of the multidimensional scaling solution obtained.

\section{DISCUSSION}

The basic similarities between the variables contained in the different models examined here is, we believe, an important finding for the advancement of research on understanding individual health-related behaviors. It suggests that the models are far from independent; rather, despite differences in the labeling and defining of variables, there is substantial overlap among the variables contained in the different frameworks, as judged by the model builders themselves. The results of combining the variables from the different models provide a more complete representation of the factors which are thought to influence health actions.

The set of major variable categories which emerged from these analyses includes: (1) items pertaining to accessibility of health services, such as the individual's ability to pay for health care and awareness of health services, and availability of health services; (2) items dealing with the individual's attitudes toward health care, such as beliefs in the benefits of treatment and beliefs about the quality of medical care provided; (3) items concerning the threat of illness, such as the individual's perception of symptoms and beliefs about susceptibility to, and consequences of, disease; (4) items pertaining to knowledge about disease; (5) items dealing with the individual's social interactions, social norms, and social structure; and (6) items on demographic characteristics (social status, income, and education).

Finally, the spatial representation of items provided information on the association between clusters of variables in three dimensions (however, no attempt is made to examine possible relationships between clusters of variables and the three spatial dimensions, and none were obvious from the results of the solution). The items pertaining to knowledge of disease were located in close proximity to the items dealing with perception and evaluation of symptoms and the items on social interactions. Although the specific causal linkages are unknown, one might reasonably speculate that knowledge about disease is exchanged through one's social interactions, and that this information is used in making judgments about symptoms and the threat of disease. Similarly, the close proximity of items dealing with the individual's attitudes toward health care and items on accessibility to health services suggests a relationship in which access factors affect and/or are affected by one's evaluation of health care. The close proximity between demographic variables and access to health service variables suggests a relationship in which accessibility is a function of an individual's 
social class [such a relationship has, of course, been frequently documented (McKinlay, 1972; Anderson and Bartkus, 1973; Anderson, 1973)] .

According to Leventhal (1978), models serve two functions: (1) to focus attention on certain factors while leading us to ignore others, usually factors that do not fit the model; and (2) to make predictions about what should happen in specific settings under certain conditions. While this study attempts to lay the groundwork for further model-testing by presenting a general framework for describing behavior, it does not address questions about the possible causal associations which may exist between factors or about why certain factors are important in one population but not in another. The attribution of causal effects can be accomplished through causal models which incorporate theory, knowledge about the population, knowledge about the setting, and knowledge about the specific behavior under investigation. Explicit statements of theory are essential for worthwhile theory-based research. The next step, which involves testing hypotheses about the causal relationships among the major clusters described here, will force the researcher to make explicit all causal assumptions in an internally consistent system. Together with population-specific data, this type of information is prerequisite to the development of effective strategies for modifying health-related behavior.

\section{SUMMARY}

Ninety-nine variables representing the 14 models examined in this study were found, upon evaluation by expert judges (the model builders themselves) and subsequent inspection by Smallest Space Analysis, to cluster into six broad factors. The six factors include (1) accessibility to health care, (2) evaluation of health care, (3) perception of symptoms and threat of disease, (4) social network characteristics, (5) knowledge about disease, and (6) demographic characteristics. Comparisons across judges' partitionings of the model variables revealed considerable agreement, providing evidence for the stability of the multidimensional scaling solution and demonstrating that the model builders themselves see little distinction among related variables which have been labeled and/or defined differently. The results of the study provide a first step in developing a unified framework for explaining health actions. Additional research is needed to test the causal processes among variables which are implied by various theories through the use of causal models.

\section{APPENDIX. MODEL VARIABLES AND THEIR DEFINITIONS}

1. Perceptual salience of symptoms - Perceived importance of symptoms.

2. Perceived seriousness of symptoms-Estimates of present and future probabilities of danger associated with symptoms. 
3. Extent to which symptoms disrupt social activities - Symptoms which cause inconvenience, social difficulties, pain, and annoyance.

4. Frequency of occurrence and persistence of symptoms - Frequent and persistent symptoms are more likely to influence a person to seek help than occasional or recurring symptoms.

5. Tolerance threshold regarding deviant signs and symptoms-Person's tolerance for pain and discomfort and his values about stoicism and independence affect response to symptoms.

6. Available information, knowledge, and cultural assumptions - The sophistication of patients about medical matters varies from those who are aware of the latest new therapeutic developments to those who hold very naive notions about bodily functioning.

7. Perceptual need which leads to avoidance - Extent to which denial tendencies, in part motivated by psychological need to maintain the situation under control, influences the recognition of symptoms and delay in seeking care.

8. Need competing with illness response - Behavior takes place within a context where motives are frequently competing or are in conflict.

9. Availability of treatment resources - Distance to health service, convenience, availability of particular practitioner.

10. Monetary costs of taking action - Financial costs associated with taking a particular health action.

11. Psychological costs of taking action - Acceptability of facilities, embarrassment or shame associated with taking action, cultural expectations, anticipation of humiliation resulting from treatment, degree of stigma or social threat implied in using service.

12. Aspiration for self - Individual's level of striving and aspirations for the future.

13. Willingness to recommend behavior to others - Individual's willingness to recommend health action to family and friends.

14. Knowledge concerning health action - Awareness and understanding of health action, such as a particular method.

15. Knowledge of the availability of health service - Awareness of available health facilities which provide particular kinds of health service.

16. Conjugal power structure - Amount of influence assumed in family decision by either the husband or the wife.

17. Extraspouse communication - Extent to which the individual discusses specific problems with people other than their spouse.

18. Conjugal communication - Amount of discussion between husband and wife on specific issues such as expenditures, politics, and use of health services.

19. Sources of information - Individual's sources of information on different issues (e.g., interpersonal sources - friends and relatives; nonpersonal sources - mass media).

20. Topics on which information is sought - Types of information a person seeks out most frequently. 
21. Attitudes toward health-related goal-Perception of norms associated with a particular health action.

22. Attitudes toward health action - Intention to take health action.

23. Attitudes toward providers of care - Perceptions concerning providers of care such as helpfulness and caring.

24. Past experience - Past experience with illness and/or health action.

25. Traditional/Modern - Participation in social groups, use of modern technology.

26. Availability of health services - Perceived access to care.

27. Situational constraints - Factors which intervene between intention to take health action and behavior.

28. Quality of care - Satisfaction with health care received in the past.

29. Social support - Perceived approval of health action by spouse, other relatives, and friends.

30. Perceived susceptibility - Individual's belief regarding the likelihood of a particular condition occurring.

31. Perceived severity - Individual's belief that the occurrence of a condition would have a moderately serious impact on life.

32. Perceived benefits - Individual's belief that there are actions which would be beneficial in reducing his susceptibility to and/or the severity of the condition should it occur.

33. Perceived barriers/costs - Individual's belief concerning the costs associated with taking a health action.

34. General health motivation - Individual's concern for health matters in general.

35. Internal/external locus of control - Individual's perception of his control over both personal health matters and life in general.

36. Cues to action - Stimulus or cue, which may be internal or external, to the individual which triggers appropriate health behavior.

37. Non-kin interaction - Frequency with which an individual interacts with people who live outside one's immediate residential area.

38. Conjugal structure - Sex role differentiation and influence in family decision making.

39. Situation constraints - Number of dependents in a household and number of instrumental tasks involving the respondent.

40. Socioeconomic status - Combined measure of the individual's educational level and family income.

41. Neighborhood socioeconomic status - Score reflecting socioeconomic status assigned to census tract where individual resides.

42. Perceived efficacy - Probability that health action will lead to the desired outcome.

43. Costs/Barriers - Unpleasantness or cost of taking the health action compared with taking no action and suffering the consequences. 
44. Past utilization of medical services - Past use of health services in general.

45. Factual information - Information concerning the health action and health condition in question (e.g., danger of the disease, knowledge of the prescribed medical regimen).

46. Psychological distress - Feelings of distress and discomfort arising from the identification of symptoms.

47. Self-acceptance - Willingness to adopt the sick role.

48. Threshold for pain - Individual's perception of pain sensations.

49. Tolerance of disability - Individual's willingness to accept disability associated with illness condition.

50. Illness disvalues - Individual's evaluation of the illness's meaning and/or significance. It is assumed that every illness is associated with a set of undesirable features or components (e.g., presumed danger to life, degree of disability).

51. Assessment of treatment plans-Estimate of the probability that a treatment plan will alleviate a negative component or disvalue of illness.

52. Treatment benefits - Assessment of the potential benefits that can be accrued from various treatment plans. Benefits are assumed to represent the amount of disvalue that is eliminated by a treatment plan.

53. Treatment costs - Estimate of the costs associated with a treatment plan (e.g., time lost from work, monetary costs, loss of personal control).

54. Net benefits or utility - Costs of the treatment plan subtracted from the potential benefits of the same treatment plan.

55. Fear-Feelings of fear regarding specific features of the disease (e.g., discomfort, disfiguration) and subsequent consequences of the disease.

56. Features of the sources of care - Cost and location of service, individual's opinion concerning quality of medical care provided.

57. Social factors - Individual's perceptions of the attitudes of friends and relatives concerning a particular health action and knowledge of others' past health behaviors.

58. Beliefs concerning the value of health services - Six-item Guttman scale with questions on the individual's beliefs about value of home remedies, need for medical aid, assessment of modern medicine, control over health.

59. Beliefs concerning the value of physicians - Five-item Guttman scale with questions on the evaluation of care received from doctors, assessment of the status of the medical profession, importance of choosing a doctor, doctors' interest in their incomes.

60. Beliefs concerning the value of good health - Nine-item Guttman scale on the likelihood of making changes in lifestyle if doctors said it was necessary to protect health (e.g., stop eating favorite foods, get more exercise).

61. Beliefs concerning the value of health insurance - Two-item index including the individual's judgments concerning the value of health insurance which covers expenses only with participating hospitals and doctors and the value of some kind of insurance which covers all medical expenses. 
62. Knowledge about disease in general - Ten-item index based on agreement that each of ten symptoms might be early signs associated with disease (e.g., shortness of breath related to heart disease, coughing and spitting up of blood related to tuberculosis).

63. Attitudes concerning the use of different health services - Six-item Guttman scale with questions on the individual's beliefs about when to seek medical care and avoiding seeing a doctor.

64. Attitudes concerning physician use - Six-item Guttman scale with questions on the individual's beliefs about seeing a doctor in the presence of symptoms such as diarrhea, high fever, loss of weight.

65. Family resources - Family's ability to pay for health services.

66. Community resources - Availability of health services, convenience, health education level in the community (e.g., scientific knowledge of medicine as opposed to folk knowledge of medicine).

67. Perception of health status - Individual's perception of physical condition which is considered less than optimal (e.g., recognition of symptoms, disability days).

68. Family composition - Age, sex, and marital status of the head of household, family size, age of the youngest and oldest family members.

69. Social structure - Characteristics of the family's main earners such as employment, social class, occupation, educational level, race and ethnicity.

70. Ethnic exclusivity - Refers to the tendency of an individual to interact with persons with the same ethnic and social background.

71. Knowledge about disease-Understanding of etiology, symptoms, and prognosis of various diseases.

72. Friendship solidarity - Refers to the degree to which the individual belongs to a close friendship group(s) of long duration.

73. Orientation to family tradition and authority - Refers to the importance placed by the individual's family upon customs, traditions, and the degree of authority possessed by the head of the household.

74. Skepticism of medical care - Doubts the individual has about the claims of professional medicine and his desire to check on who the doctor is and what he is doing.

75. Dependency in illness - Need of the sick individual to rely upon others for help and support during illness.

76. Appraisal of the adequacy of care provided by various health facilities Individual's evaluation of different providers of medical care.

77. Perception of friends' appraisal of the adequacy of alternative health services - Individual's perceptions concerning what their friends think about different health care providers.

78. Recognition of medical symptoms - Awareness and knowledge about various disease symptoms.

79. Need for medical care - Individual's perceived need for medical advice and/ or treatment. 
80. Symptom sensitivity - Individual's belief that symptoms are serious enough to require consulting a doctor.

81. Ability to pay for health service - Indicated by whether an individual has health insurance.

82. Availability of health sercices - Distance an individual is from health care facilities.

83. Regular family physician - Individual's report of having a regular family doctor.

84. Avoidance of ill health - Willingness on the part of the individual to spend a lot of money on health care.

85. Approval of friends - Discussion with friends about health care.

86. Effective motivation - Belief that a particular health action would be effective in avoiding illness.

87. Knowledge - Awareness of certain facts about disease.

88. Anxiety - Hesitation about engaging in a health action because of possible pain or discomfort associated with that action.

89. Financial difficulty - Ability to pay for health care.

90. Assessment of symptoms - Difference between the present functioning of health and its previous or usual functioning. Any disturbance must reach a certain degree of seriousness or duration in order to be assessed as a symptom.

91. Specific anxiety - Anxiety aroused as a result of the assessment of specific symptoms.

92. Floating anxiety - Anxiety which is preexistent to and independent from the morbid episode. Anxiety which is a function of psychological and social forces.

93. Pertaining knowledge - General body of knowledge about health; illness and therapy corresponding to the cultural, situational, and interaction patterns in the community.

94. Social pressures - Support in the form of social norms which affects one's decision to adopt certain health practices.

95. Contact and communication within one's own social stratum - Amount of contact and/or communication with adopters or nonadopters within one's own social stratum.

96. Social participation - Amount of participation with other people through social groups or informal relationships.

97. Relative advantages of action - Individual's judgment regarding the relative merits of a certain action compared to other actions.

98. Contact and communication outside one's own social stratum - Amount of contact and/or communication with adopters or nonadopters outside one's own social stratum.

99. Compatability with existing values, past experiences, and needs of the individual - Extent to which an action is compatible with the individual's values, past experiences, and needs. 


\section{ACKNOWLEDGMENTS}

The authors wish to thank Robert Reynolds and Dr. James Lingoes for their assistance in processing the data for this paper and for their many useful suggestions regarding the analyses. We also gratefully acknowledge the critical participation of Drs. Ronald Andersen, Horacio Fabrega, Jr., Lawrence Green, Snehendu Kar, Stanislav Kasl, Jean Langlie, David Mechanic, and Irwin Rosenstock, who served as the panel of expert judges.

\section{REFERENCES}

Andersen, R. (1968). A Behavioral Model of Families' Use of Health Services, Center for Health Administration Studies, University of Chicago, Chicago.

Anderson, J. G. (1973). Demographic factors affecting health service utilization: A causal model. Med. Care 11: 104-120.

Anderson, J. G., and Bartkus, D. E. (1973). Choice of medical care: A behavioral model of health and illness behavior. J. Health Soc. Behav. 14: 348-362.

Antonovsky, A., and Kats, R. (1970). The model dental patient: An empirical study of preventive health behavior. Soc. Sci. Med. 4: 367-379.

Barofsky, I. (ed.) (1977). Medication Compliance: A Behavioral Management Approach, Charles B. Slack, Thorofare, N.J.

Fabrega, H. (1973). Toward a model of illness behavior. Med. Care 11: 470-484.

Fabrega, H. (1974). Disease and Social Behavior: An Interdisciplinary Perspective, Massachusetts Institute of Technology Press, Cambridge.

Fleiss, J. L. (1973). Statistical Methods for Rates and Proportions, John Wiley and Sons, New York.

Green, L. W. (1975). Diffusion and adoption of innovations related to cardiovascular risk behavior in the public. In Enelow, A. J., and Henderson, J. B. (eds.), Applying Behavioral Science to Cardiovascular Risk-Proceedings of a Conference, American Heart Association, Washington, D.C.

Guttman, L. (1968). A general non-metric technique for finding the smallest coordinate space for configuration of points. Psychometrika 33: 469-506.

Hochbaum, G. M. (1958). Public Participation in Medical Screening Programs: A SocioPsychological Study, U.S. Government Printing Office, Washington, D.C.

Kar, S. B. (1977). Community interventions in health and family planning programmes A conceptual framework. Int. J. Health Educ. 20: No. 1 (Suppl.).

Kar, S. B. (1978). Consistency between fertility attitudes and behavior: a conceptual model. Pop. Studies 32: 173-185.

Kasl, S. V., and Cobb, S. (1966a). Health behavior, illness behavior, and sick role behavior. I. Health and illness behavior. Arch. Environ. Health 12: 246-266.

Kasl, S. V., and Cobb, S. (1966b). Health behavior, illness behavior, and sick role behavior. II. Sick role behavior. Arch. Environ. Health 12: 531-541.

Kirscht, J. P., Becker, M. H., Haefner, D. P., and Maiman, L. A. (1978). Effects of threatening communications and mothers' health beliefs on weight change in obese children. J. Behav. Med. 1: 147-157.

Kosa, J., and Robertson, L. S. (1975). The social aspects of health and illness. In Kosa, J., and Zola, I. (eds.), Poverty and Health: A Sociological Analysis, Harvard University Press, Cambridge.

Langlie, J. K. (1977). Social networks, health beliefs, and preventive health behavior. $J$. Health Soc. Behav. 18: 244-260.

Leventhal, H. (1978). Patient behavior. In Patient Education in the Primary Care Setting Proceedings of the Second Conference. Center for Health Services, University of Wisconsin, Madison. 
Lingoes, J. C., (ed.) (1977). Geometric Representations of Relational Data, Mathesis Press, Ann Arbor.

McKinlay, J. B. (1972). Some approaches and problems in the study of the use of services An overview. J. Health Soc. Behav. 13: 115-152.

Mechanic, D. (1968). Medical Sociology: A Selective View, The Free Press, New York. Napier, D. (1972). Nonmetric multidimensional scaling techniques for summated ratings. In Shepard, R. N., et al. (eds.), Multidimensional Scaling - Vol. 1, Seminar Press, New York.

Rosenstock, I. M. (1966). Why people use health services. Milbank Mem. Fund Q. 44: 94-124 (Part 2).

Sackett, D. L., and Snow, J. C. (1979). The magnitude of compliance and noncompliance. In Haynes, R. B., et al. (eds.), Compliance in Health Care, The Johns Hopkins University Press, Baltimore.

Shepard, R. N., Romney, A. K., and Nerlove, S. B. (1972). Multidimensional Scaling: Theory and Applications in the Behavioral Sciences, Vol. 1, Academic Press, New York.

Suchman, E. A. (1966). Health orientation and medical care. Am. J. Publ. Health 56: 97-105. 